\title{
Genome
}

\section{Karyotype structure and cytogenetic markers of Amoimyrmex bruchi and Amoimyrmex silvestrii: the contribution to understanding leafcutting ant relationships}

\begin{tabular}{|c|c|}
\hline Journal: & Genome \\
\hline Manuscript ID & gen-2021-0044.R2 \\
\hline Manuscript Type: & Article \\
\hline $\begin{array}{r}\text { Date Submitted by the } \\
\text { Author: }\end{array}$ & 14-Aug-2021 \\
\hline Complete List of Authors: & $\begin{array}{l}\text { Micolino, Ricardo; Universidade Federal do Paraná } \\
\text { Baldez, Brenda; Universidade Federal de Ouro Preto - Campus Morro do } \\
\text { Cruzeiro } \\
\text { Sánchez Restrepo, Andrés Fernando; Fundación para el Estudio de } \\
\text { Especies Invasivas } \\
\text { Calcaterra, Luis; Fundación para el Estudio de Especies Invasivas } \\
\text { Cristiano, Maykon; Universidade Federal de Ouro Preto - Campus Morro } \\
\text { do Cruzeiro } \\
\text { Cardoso, Danon; Universidade Federal de Ouro Preto, Departamento de } \\
\text { Biodiversidade, Evolução e Meio Ambiente }\end{array}$ \\
\hline Keyword: & $\begin{array}{l}\text { Karyotype, Chromosome number, Cytogenetic, Evolution, Fungus- } \\
\text { farming }\end{array}$ \\
\hline $\begin{array}{r}\text { Is the invited manuscript for } \\
\text { consideration in a Special } \\
\text { Issue? : }\end{array}$ & Not applicable (regular submission) \\
\hline
\end{tabular}

\section{SCHOLARONE ${ }^{\text {M }}$ \\ Manuscripts}


1 Karyotype structure and cytogenetic markers of Amoimyrmex bruchi and

2

3

4

5 Ricardo Micolino ${ }^{1}$

6 Brenda Carla de Lima Baldez ${ }^{2,3}$

7 Andrés F. Sánchez-Restrepo ${ }^{4,5}$

8 Luis Calcaterra 4,5

9 Maykon Passos Cristiano 2,3

Danon Clemes Cardoso 1,2,3* Brazil. Preto, Ouro Preto, MG, Brazil. Argentina. Argentina.

\section{Acknowledgments}

${ }^{1}$ Programa de Pós-graduação em Genética, Universidade Federal do Paraná, Curitiba, PR,

${ }^{2}$ Departamento de Biodiversidade, Evolução e Meio Ambiente, Universidade Federal de Ouro Preto, Campus Morro do Cruzeiro, Ouro Preto, MG, Brazil.

${ }^{3}$ Programa de Pós-gradução em Ecologia de Biomas Tropicais, Universidade Federal de Ouro

${ }^{4}$ Fundación para el Estudio de Especies Invasivas (FuEDEI), Hurlingham, Buenos Aires,

${ }^{5}$ Consejo Nacional de Investigaciones Científicas y Técnicas (CONICET), Buenos Aires,

*Corresponding author: danon@ufop.edu.br Universidade Federal de Ouro Preto - UFOP, Grupo de Pesquisa em Genética e Evolução de Formigas - GEF. Campus Morro do Cruzeiro, Ouro Preto, Minas Gerais, Brazil. 35400-000.

Running title: Karyotype and cytogenetic markers of Amoimyrmex

We are grateful to the many people who made this work possible. We thank all of our colleagues at the Lab and Research Group of Genetics and Evolution of Ants (GEF-UFOP) for their help with data assembly. MPC and DCC wish to thank the Conselho Nacional de Desenvolvimento Científico e Tecnológico - CNPq (309579/2018-0 and 312900/2020-1, respectivelly) for providing financial support. LC and ASFR are both funded by Conicet and the FuEDEI. The permits for collection and transportation were administered by ASFR. Argentina permits: 
Administración Parques Nacionales (APN), Argentina, No. CRCE29, Ministerio de Agua, Ambiente y Servicios Públicos, Secretaría Ambiente, Córdoba Province, Argentina. We thank the two colleagues from PRS for the English proofreading. We also thank the editor and the reviewers for their helpful comments on the manuscript.

\section{Abstract}

Leafcutting ants are considered the most important herbivores in terrestrial environments throughout the Neotropics. Amoimyrmex Cristiano, Cardoso \& Sandoval, 2020 is the sister clade of the remaining leafcutter ants from the genera Atta and Acromyrmex. Amoimyrmex striatus was the only species cytogenetically studied within the genus and shares the same chromosomal number with Atta, bearing 22 chromosomes, whereas Acromyrmex bears 38 chromosomes, with the exception of the social parasite Acromyrmex ameliae $(2 n=36)$. Our objective here was to analyze cytogenetically the species of Amoimyrmex bruchi and Amoimyrmex silvestrii, as well as to describe the karyotype of these sister species, by means of an integrative approach using classical and molecular cytogenetics. We aimed to characterize cytogenetic markers that contribute to the systematics and taxonomy of the genus. Our results showed that the karyotypes of these two species are very similar, with an identical chromosome number $(2 n=22)$, chromosome morphology $(2 \mathrm{~K}=20 \mathrm{~m}+2 \mathrm{sm})$, and location of $18 \mathrm{~S}$ rDNA and the telomeric repeat TTAGG on the chromosomes. Yet, the microsatellite probe $\mathrm{GA}_{(15)}$ showed variation across the species and populations studied. We suggest that both species diverged relatively recently and are unmistakably sisters because of the many shared characteristics, including the highly conserved karyotypes.

\section{Keywords: Karyotype, Chromosome number, Cytogenetic markers, Evolution, Fungus-}

\section{farming ants}

\section{Introduction}

Leafcutting ants comprise species from the genera Acromyrmex Mayr, 1865, Atta Fabricius 1804, and now Amoimyrmex Cristiano, Cardoso \& Sandoval, 2020. They have an obligatory symbiosis with specific basidiomycete fungi that they grow for food in elaborate gardens. Worker ants provide fresh plant material to the fungus, which produces specialized hyphal tips (gongylidia) as the primary food source for the entire colony (Hölldobler and Wilson 2011). About 20 million years ago, leafcutter ants evolved to become the dominant herbivores of 
terrestrial environments in the Neotropical region (Branstetter et al. 2017). This trait has led them to be of high economic importance due to the considerable losses they cause for a variety of crops (Hölldobler and Wilson 2011; Zanetti et al. 2014).

Despite the prominent karyotypic diversity within the Formicidae family, with chromosomes raging from $2 \mathrm{n}=2$ to $2 \mathrm{n}=120$ (reviewed in Lorite and Palomeque 2010), each of the three genera of leafcutting ants has a mostly conserved chromosome number. The available cytogenetic data for Atta species display a regularity in both chromosome number and morphology, all with $2 n=22$. On the contrary, Acromyrmex species display predominantly $2 n=38$, but with great variability in the morphology of their chromosomes (reviewed in Cardoso et al. 2018a). Interestingly, Amoimyrmex striatus Roger, 1863 has the same karyotype number as the Atta species $(2 \mathrm{n}=22)$, and includes most metacentric chromosomes, though it differs in the GCrich block pattern (Cristiano et al. 2013). This iconic species also shares morphological characteristics with both genera: three pairs of spines on the promesonotum, a trait shared with Acromyrmex (there are only two pairs of spines in Atta), and a smooth gastral tergum, shared with Atta (Acromyrmex has a tuberculate gaster) (Mayhé-Nunes 1991). Phylogenetic analyses have indicated that the Am. striatus clade is the sister group of the remaining leafcutting ants (Cristiano et al. 2013; Branstetter et al. 2017). This is well-supported by karyotypic information setting the ancestral number of leafcutter ants as $2 n=22$ (Pereira et al. 2018). All these data have resulted in the description of the new leafcutting genus Amoimyrmex Cristiano, Cardoso and Sandoval, 2020 (Cristiano et al. 2020).

Amoimyrmex is restricted to grassland habitats in subtropical and temperate zones of southern South America, occurring on the southern Brazilian coast (known as the restinga ecosystem), on sandy soils across the Pampas and Chaco, and from the southernmost part of Paraguay to the temperate savannas of the Low Monte in Argentina (Kempf 1972; compiled in Janicki et al. 2016). Recent paleodistribution analyses have identified that the potential distribution of the species may have gone through oscillations arising from the last glacial period, from which it would have expanded dramatically from the Pampas to the grasslands of Argentina (Cristiano et al. 2016). Thus, it is assumed that Amoimyrmex has been strongly influenced by changes in the connections between the Amazon River Basin and the Parana River Basin, as well the expansions and contractions of open and dry areas in the southern lowlands, disrupting populations and promoting diversification of Amoimyrmex (Cristiano et al. 2020).

Karyotype changes, including chromosome number and morphology, are speculated to promote species diversification events through chromosomal rearrangements that may later result in barriers to gene flow (Rieseberg 2001; Faria and Navarro 2010). In ants, such considerations can occur at various levels, including intraspecific variations involving the maintenance of different karyotypes in the same population, many of them between sister species or closely related species (e.g., Imai et al. 1977; Crosland et al. 1988; Hirai et al. 1996; Cardoso et al. 2014; 
Micolino et al. 2019a). Intraspecific variation among populations has been identified for a range of ants and may help in the identification of cryptic species. For example, such findings were obtained by fluorescence in situ hybridization (FISH)-based molecular cytogenetics using microsatellites and/or ribosomal DNA (rDNA) probes (Micolino et al. 2019a, 2019b), as well as standardized chromosome measurement analysis (i.e., karyomorphometry) associated with genome size (Cardoso et al. 2018b). Such comparative analysis looking for karyotype variations among geographically isolated populations could help to understand the evolution of the distribution of particular species or populations. Natural species obviously do not respect the boundaries established by mankind, but because of traditionally dubious taxonomy, and nesting sites that only differ slightly, it is worth examining cytogenetically other Amoimyrmex species from the Argentine Chaco while seeking a minor distinction from their putative, older Brazilian relatives. Therefore, karyotype description of any of these lineages would shed light on the evolution of the group and may give valuable indications of kinship and further evidence of its systematics and taxonomy.

The aim of this study was to analyze cytogenetically Amoimyrmex bruchi and Amoimyrmex silvestrii from the Chaco biome in Argentina, as well as to describe the hitherto unknown karyotype of the species, looking for cytogenetic markers that differentiate the lineages. To this aim, we used a karyomorphometric approach and FISH chromosomal mapping with ribosomal, telomeric, and microsatellite probes.

\section{Material and methods}

Colony sampling: The colonies of Am. silvestrii were collected along the Argentine Chaco at the following sampling points within the Córdoba Province: Four colonies in Tanti (-31.3505,64.5338) - Pop. A, one colony in Ruta Nacional 38/Ischilín (-30.6893,-64.6452) - Pop. B, and two colonies in Punilla (-31.3482,-64.5345) - Pop. C. Three colonies of Am. bruchi were collected around the city of Chamical in La Rioja Province, Argentina (-30.3749, -66.2809). All sampled colonies are under the domain of the Dry Chaco ecoregion, set in areas of Tropical and Subtropical Grasslands, Savannas and Shrublands, according to Dinerstein et al. (2017). A total of 62 individuals of Am. silvestrii and 31 of Am. bruchi were sampled.

Chromosome preparations: Metaphase chromosomes were obtained using brain ganglia of prepupal larvae dissected in colchicine hypotonic solution (0.005\%) according to Imai et al. (1988), with modifications described by Cardoso et al. (2012). Were obtained 31 and 62 slides for Am. bruchi and Am. silvestrii, respectively. Then, the metaphases were conventionally stained with 4\% Giemsa ${ }^{\circledR}$ solution diluted in Sørensen's buffer ( $\mathrm{pH}$ 6.8) to determine the chromosome number and morphology. The karyotype structure was described by the chromosomal arm ratio proposed 
by Levan et al. (1964) and classified according to their centromeric position: metacentric (m), submetacentric (sm), subtelocentric (st), and telocentric (t). A total of 60 and 120 metaphases of Am. bruchi and Am. Silvestrii, respectively, were analyzed. The 10 best metaphases stained with Giemsa with chromosomal integrity, identical condensation, and non-overlapping and evident centromeres were measured by the Image Pro Plus ${ }^{\circledR}$ software 4.5 (Media Cybernetics, Silver Spring, USA). Chromosomes were evaluated according to the following characteristics: total length (TL), long arm length (L), short arm length (S), long arm to short arm ratio $(r=\mathrm{L} / \mathrm{S})$, relative length of chromosomes (RL), and centromeric index $(\mathrm{S} /[\mathrm{L}+\mathrm{S}])$, as specified in the standard protocol by Cristiano et al. (2017) and Peruzzi and Eroglu (2013). Karyotypes were assembled by the Corel ${ }^{\circledR}$ PHOTO-PAINT software v.22 (Corel Corp, Ottawa, Ontario).

Fluorescence in situ hybridization (FISH): The FISH procedure for mapping repetitive DNA sequences through $18 \mathrm{~S}$ rDNA, telomeric $\mathrm{TTAGG}_{(6)}$, and microsatellite $\mathrm{GA}_{(15)}$ probes was performed according to the partial description by Kubat et al. (2008), with the appropriate modifications specified and detailed by Micolino et al. (2019b). The $\mathrm{TTAGG}_{(6)}$ and $\mathrm{GA}_{(15)}$ probes were labeled a priori, with Cy3 at the 5' end during synthesis (Sigma, St. Louis, MO, USA), while the $18 \mathrm{~S}$ rDNA probe was obtained by polymerase chain reaction (PCR) amplification (see Micolino et al. 2019b). In summary, the process involved several washes with saline solutions, followed by denaturation with formamide, and dehydration by ethanol until hybridization of the FISH probe. After overnight maintenance, the chromosome slides were washed again, dehydrated to remove the excess probe, and then put through the final assembly process in DAPI antifading solution (DAPI Fluoroshield, Sigma-Aldrich). The final step consisted of analyzing the chromosome slides under an Olympus BX53 (Olympus Corporation, Tokyo, Japan) epifluorescence microscope using the WU $(330-385 \mathrm{~nm})$ and WG $(510-550 \mathrm{~nm})$ filters for DAPI and rhodamine, respectively. Chromosome images were obtained using a MX10 digital camera (Olympus Corporation, Tokyo, Japan) attached to the microscope and using the CellSens software (Olympus Corporation, Tokyo, Japan). Subsequently, the metaphase photos were edited by using the Adobe Photoshop CC ${ }$ software (Adobe Systems Incorporated, San Jose, USA).

\section{Results}

The studied populations of Am. silvestrii displayed metaphases with a diploid chromosome number of $2 \mathrm{n}=22$ consisting of 10 metacentric chromosomal pairs and one submetacentric pair; their karyotype formula was $2 \mathrm{~K}=20 \mathrm{~m}+2 \mathrm{sm}$, and they had a fundamental number of $\mathrm{NF}=44$ (Fig. 1). Likewise, the Am. bruchi karyotype displayed exactly the same characteristics as Am. silvestrii (Fig. 1). The karyomorphometric data of Am. silvestrii chromosomes in this work were as follows: the total chromosome length for population A ranged 
from $3.88 \pm 0.48 \mu \mathrm{m}$ to $2.33 \pm 0.33 \mu \mathrm{m}$ and centromeric index ranged from $0.30 \pm 0.02 \mu \mathrm{m}$ to $0.48 \pm 0.02 \mu \mathrm{m}$ (Table S1), while the total length of all chromosomes was $59.35 \mu \mathrm{m}$ (Table 1); population B presented a total chromosome length ranging from $3.99 \pm 0.58 \mu \mathrm{m}$ to $2.38 \pm 0.35 \mu \mathrm{m}$, centromeric index ranged from $0.31 \pm 0.00 \mu \mathrm{m}$ to $0.49 \pm 0.00 \mu \mathrm{m}$ (Table S2) and a total length of all chromosomes of $60.35 \mu \mathrm{m}$ (Table 1); in population $\mathrm{C}$, the total length of chromosomes ranged from $4.05 \pm 0.63 \mu \mathrm{m}$ to $2.34 \pm 0.42 \mu \mathrm{m}$, centromeric index ranged from $0.31 \pm 0.00 \mu \mathrm{m}$ to $0.49 \pm 0.01$ $\mu \mathrm{m}$ (Table S3), while the total length of all chromosomes was $59.35 \mu \mathrm{m}$ (Table 1). In Am. bruchi, chromosome measurements ranged from $3.98 \pm 0.52 \mu \mathrm{m}$ to $2.61 \pm 0.29 \mu \mathrm{m}$, centromeric index ranged from $0.32 \pm 0.03 \mu \mathrm{m}$ to $0.48 \pm 0.02 \mu \mathrm{m}$ (Table S4), with the total length of all chromosomes being $60.29 \mu \mathrm{m}$ (Table 1).

FISH chromosomal mapping performed for the three Argentine populations of $A m$. silvestrii and the Am. bruchi displayed no significant differences in either the number or the brightness of the of $18 \mathrm{~S}$ and TTAGG probes. The probe for the $18 \mathrm{~S}$ rDNA cluster was labeled on only one chromosomal pair in all samples, located in the interstitial region of the long arms of the second pair of metacentric chromosomes (Fig. 2). The $\mathrm{TTAGG}_{(6)}$ telomeric repeat distribution pattern was restricted to the ends of both arms on all chromosomal pairs. In addition, no signal for interstitial telomeric sites (ITS) was observed (Fig. 2). The $\mathrm{GA}_{(15)}$ microsatellite probe provided a rich band pattern in the subtelomeric regions of some specific chromosomes, extending more interstitially across both chromosomal arms, with some signals remarkably stronger than others. Weaker markings could be observed on the smaller chromosomes, suggesting a shortage of this repeat in them. In general, the $\mathrm{GA}_{(15)}$ probe produced a scattered distribution along the chromosomes with a different number of markings between Am. silvestrii population A versus B and C. For population A, all chromosomes had microsatellite markings, whereas for populations $\mathrm{B}$ and $\mathrm{C}$, there was a small metacentric chromosome negative for $\mathrm{GA}_{(15)}$. Yet, Am. bruchi presented two metacentric chromosomes negative for $\mathrm{GA}_{(15)}$. This pattern was recurrent for all samples analyzed (Fig. 2).

\section{Discussion}

The results of our comparative cytogenetic work showed that the diploid number of chromosomes in representatives of the three Am. silvestrii populations, as well as in the Am. bruchi population, was invariably $2 \mathrm{n}=22$. The karyomorphometric analysis revealed that the karyotype in all samples consists of 10 metacentric pairs and one submetacentric pair. We have described, for the first time, the karyotype of Am. silvestrii and Am. bruchi, a prospective sister lineage belonging to what we call the leafcutting ants. Ongoing phylogenetic analyses support this degree of closeness (Cristiano et al. 2020). We also demonstrated that the karyotypes of $\mathrm{Am}$. silvestrii and Am. bruchi are very similar: They showed no differences in our cytogenetic surveys. 
222 It seems that the diversification in Amoimyrmex has not been accompanied by substantial 223 chromosomal rearrangements We therefore suggest that both species have diverged relatively recently, owing to many shared and conserved characteristics, including their karyotypes.

The results of karyotype length in Amoimyrmex species corroborate the previous findings of Pereira et al. (2018) and differ a little from those of Cristiano et al. (2013), which ranged from $5.78 \pm 0.15 \mu \mathrm{m}$ to $1.77 \pm 0.05 \mu \mathrm{m}$ and a total length of $78.67 \mu \mathrm{m}$. A possible explanation for this incongruence is that the karyomorphometric protocol used by our group has undergone successive improvements and standardizations, making it increasingly close to the appropriate one, which further corroborates genome size estimation by flow cytometry (see Cristiano et al. 2017; Cardoso et al. 2018b). The karyotype of Am. silvestrii and Am. bruchi showed a pronounced structural and numerical similarity with $A$. striatus, including the length of the chromosomes. Population-based chromosomal studies may reveal often unreached intraspecific diversity either by morphological means (e.g., cryptic species), molecular means (e.g., weak phylogenetic signal), or other methods (e.g., Talavera et al. 2013; Lukhtanov and Shapoval, 2017). For example, a karyomorphometric analysis of Mycetomoellerius holmgreni fungus-farming ant populations revealed significant differences in karyotype length, suggesting that this ant species might be undergoing centromere drive (Cardoso et al. 2018b). In a further analysis of those populations, cytogenetic markers by means of microsatellite probes were population specific, a finding that corroborates the potential restriction to gene flow among the studied populations of Mycetomoellerius holmgreni (Micolino et al. 2019b).

Our results for the physical mapping of the $18 \mathrm{~S}$ rDNA cluster and the TTAGG telomeric motif are consistent with the previously described data for Am. striatus in the Brazilian ecosystems of the restingas and the Pampas (Teixeira et al. 2017; Pereira et al. 2018). An interesting cytogenetic feature of Am. striatus is the location of the 18S rDNA cluster, identified in the interstitial region of a pair of metacentric chromosomes, similar to those found for Atta species (Teixeira et al. 2017). Likewise, the location of the 18S rDNA cluster in Am. silvestrii and Am. bruchi was indistinguishable from Am. striatus. The rDNA is one of the most conservative fractions of the eukaryotic genome, and ribosomal RNA genes have changed minimally throughout evolutionary history (Raskina et al. 2008). Despite this conservation, rDNA is a strong source of genome instability, of which rDNA dynamics are an indicator of significant intragenomic processes (Raskina et al. 2004). It is therefore somewhat apparent that Am. striatus would have the ancestral karyotype structure of the clade of leafcutter ants, in terms of the number and the location of the $18 \mathrm{~S}$ rDNA on the chromosomes. Clearly, this assumption has greater support from molecular data (e.g., Cristiano et al. 2013, 2020; Pereira et al. 2018), although it is noteworthy that an integrative approach (cytogenetic and molecular data) involving extensive sampling would support such a point remarkably well. 
The TTAGG telomeric repeat is considered to be the ancestral motif of insects

259

260

261

262

263

264

265

266

267

268

269

270

271

272

273

274

275

276

277

278

279

280

281

282

283

284

285

286

287

288

289

290

291

292

293

294 (Kuznetsova et al. 2020). In general, the order Hymenoptera has the TTAGG repeat retained in its representatives, although it has been suggested that it was putatively lost in the ancestor Apocrita with at least two subsequent independent recoveries (Menezes et al. 2017; Gokhman and Kuznetsova 2018). One of them has occurred in Formicidae and has been increasingly identified in ant telomeres (e.g., Lorite et al. 2002; Pereira et al. 2018; Micolino et al. 2019a, $2019 b$ ). One application of telomeric probes has been in the recognition of fusion rearrangements, which can also identify population polymorphisms (Ruiz-Herrera et al. 2009). Preliminary analysis with the $\mathrm{TTAGG}_{(6)}$ probe in Am. striatus revealed no interstitial telomeric signals, denoting that $2 n=22$ is the most likely ancestral karyotype of the leafcutter ants and is a plesiomorphic feature shared between Am. striatus and Atta species (Pereira et al. 2018). We observed markings for the TTAGG motif exclusively at the ends of chromosomes in all samples of Am. silvestrii and Am. bruchi analyzed here, suggesting their putative conservation within these ant lineages.

The FISH mapping results for the microsatellite $\mathrm{GA}_{(15)}$ suggest that there is distinguishable variation among samples, depicting subtly stronger markings on some chromosomal pairs. Such accumulation of these repeated sequences was observed in the subtelomeric region in both chromosomal arms. However, Am. bruchi showed two chromosomes without markings compared with only one in Am. silvestrii, indicating a different pattern of microsatellite accumulation in these chromosomes. Such differential markers of the $\mathrm{GA}_{(15)}$ probe can be used to differentiate both species. Indeed, our cytogenetic data agree with morphological and molecular data from Cristiano et al. (2020).

In fact, microsatellite repeats can be arranged in well-defined clusters on chromosomes. For example, 15 species of stingless bees of the genus Melipona displayed $\mathrm{GA}_{(15)}$ repeats in predominantly telomeric blocks (Travenzoli et al. 2019). Intraspecific cytogenetic polymorphisms have recently been found in the ant Mycetomoellerius holmgreni, showing distinct, well-defined blocks of the microsatellite $\mathrm{GA}_{(15)}$ in populations situated to the north and south of their occurrence area, denoting a potential geographic and/or reproductive isolation between them (Micolino et al. 2019b). Moreover, birds generally have a preferential accumulation of microsatellite repeats restricted to the centromeric and telomeric regions. In particular, woodpeckers showed different distribution patterns of microsatellite sequences on the $\mathrm{Z}$ sex chromosome, including the dinucleotide $\mathrm{GA}_{(15)}$ (de Oliveira et al. 2017). On the contrary, there are many findings showing such entirely scattered repeats in both heterochromatic and euchromatic regions on chromosomes (e.g., Cioffi et al. 2011; Palacios-Gimenez et al. 2015; Cunha et al. 2016). In sum, these findings suggest the particularly dynamic nature of microsatellite sequences, making them good cytogenetic markers mainly when their occurrence is nondispersive across chromosomes. 
As each organism presents its own karyotype, the chromosome number and morphology are of interest for taxonomic studies, because closely related species tend to have karyotypes more similar than phylogenetically distant ones (Sumner 2003). This was seen in Am. silvestrii and Am. bruchi, whose karyotype number and structure were identical to that of Am. striatus. Furthermore, these species strongly resemble each other morphologically, making it difficult to identify and to differentiate between them. The very similar karyotypes of the two species confer an additional characteristic in which closely related ant species can diverge without deep chromosomal changes during the speciation process. As no structural changes at the chromosomal level were identified, we suggest that perhaps changes related to genome function or regulation are more linked to divergence; this is a topic for further research.

The recognized chromosomal properties of the Amoimyrmex resemble karyotypic data in Trachymyrmex spp. (all karyotyped species have $2 \mathrm{n}=20$ ), mainly by the predominance of metacentric chromosomes and the absence of acrocentric ones (reviewed in Cardoso et al. 2018a). Considering the phylogenetic position of these two clades (Cristiano et al. 2020), we can suggest a likely evolutionary trajectory focusing on chromosome changes. The karyotype differentiation of Amoimyrmex species towards Trachymyrmex species is determined by the difference of one extra chromosomal pair and the presence of a pair of submetacentric chromosomes. Hence, there could have been a chromosomal fission in the ancestral karyotype, followed by a pericentric inversion, that changed the karyotype to its current state of $2 n=22$ comprising 10 pairs of metacentric chromosomes and one submetacentric pair. A similar scenario about the role of chromosomal inversions in the lineage diversification process has been assumed for closely related species of the genus Mycetomoellerius (Micolino et al. 2020). Overall, we have provided new karyotype data for Amoimyrmex and further cytogenetic evidence that differentiate Amoimyrmex from the remaining leafcutting ants. Such data may be useful in future comparative cytogenetic analyses. We have also provided insights into their possible phylogenetic

\section{References} (2017) Dry habitats were crucibles of domestication in the evolution of agriculture in ants Proceedings of the Royal Society Biological Sciences 284: 20170095

Bush GL, Case SM, Wilson AC \& Patton JL (1977) Rapid speciation and chromosomal evolution in mammals Ediciones Proceedings of the National Academy of Sciences of the United States of America 74: 3942-3946 
Cardoso DC, Cristiano MP, Barros LAC, Lopes DM \& Pompolo SG (2012) First cytogenetic characterization of a species of the arboreal ant genus Azteca Forel 1978 (Dolichoderinae Formicidae) - Comparative Cytogenetics 6: 107-114

Cardoso DC, Pompolo SG, Cristiano MP \& Tavares MG (2014) The role of fusion in ant chromosome evolution: insights from cytogenetic analysis using a molecular phylogenetic approach in the genus Mycetophylax - PLoS ONE 9: e87473

Cardoso DC, Santos HG \& Cristiano MP (2018a) The Ant Chromosome database - ACdb: an online resource for ant (Hymenoptera: Formicidae) chromosome researchers Myrmecological News 27: 87-91

Cardoso DC, Heinze J, Moura MN \& Cristiano MP (2018b) Chromosomal variation among populations of a fungus-farming ant: implications for karyotype evolution and potential restriction to gene flow - BMC Evolutionary Biology 18: 146

Cioffi MB, Kejnovsky E \& Bertollo LAC (2011) The chromosomal distribution of microsatellite repeats in the genome of the wolf fish Hoplias malabaricus focusing on the sex chromosomes - Cytogenetic and Genome Research 132: 289-296

Corcoran LM, Thompson JK, Walliker D \& Kemp DJ (1988) Homologous recombination within subtelomeric repeat sequences generates chromosome size polymorphisms in $P$ falciparum - Cell 53: 807-813

Cristiano MP, Cardoso DC \& Fernandes-Salomão TM (2013) Cytogenetic and molecular analyses reveal a divergence between Acromyrmex striatus (Roger 1863) and other congeneric species: taxonomic implications - PLoS ONE 8: 9

Cristiano MP, Cardoso DC, Fernandes-Salomão TM \& Heinze J (2016) Integrating paleodistribution models and phylogeography in the grass-cutting ant Acromyrmex striatus (Hymenoptera: Formicidae) in southern lowlands of South America - PLoS ONE 11 e0146734

Cristiano MP, Pereira TTP, Simões LP, Sandoval-Gómez VE \& Cardoso DC (2017) Reassessing the chromosome number and morphology of the turtle ant Cephalotes pusillus (Klug 1824) using karyomorphometrical analysis and observations of new nesting behavior - Insects 8: 114

Cristiano MP, Cardoso DC, Simões-Gomes FC, Sandoval-Gómez VE (2020) Amoimyrmex Cristiano Cardoso \& Sandoval gen nov (Hymenoptera: Formicidae): a new genus of leaf-cutting ants revealed by multilocus molecular phylogenetic and morphological analyses Austral Entomology 59: 643- 676 https://doiorg/101111/aen12493

Crosland MWJ, Crozier RH \& Imai HT (1988) Evidence for several sibling biological species centred on Myrmecia pilosula (F SMITH) (Hymenoptera: Formicidae) - Journal of the Australian Entomological Society 27: 13-14 
Cunha MS, Reis VJC \& Dergam JA (2016) Closely related syntopic cytotypes of Astyanax taeniatus (Jenyns 1842) from the Upper Piranga River Upper Doce Basin in Southeastern Brazil - Zebrafish 13:112-117

De Oliveira TD, Kretschmer R, Bertocchi NA, Degrandi TM, De Oliveira EHC, Cioffi MB, Garnero AV \& Gunski RJ (2017) Genomic organization of repetitive DNA in woodpeckers (Aves Piciformes): implications for karyotype and ZW sex chromosome differentiation PLoS ONE 12: e0169987

Dinerstein E, Olson D, Joshi A, Vynne C, Burgess ND, Wikramanayake E \& Hansen M (2017) An ecoregion-based approach to protecting half the terrestrial realm - BioScience 67: 534545

Faria R \& Navarro A (2010) Chromosomal speciation revisited: rearranging theory with pieces of evidence - Trends in Ecology and Evolution 25: 660-669

Frydrychová R, Grossmann P, Trubac P, Vítková M \& Marec F (2004) Phylogenetic distribution of TTAGG telomeric repeats in insects - Genome 47: 163-178

Gokhman VE \& Kuznetsova VG (2018) Presence of the canonical TTAGG insect telomeric repeat in the Tenthredinidae (Symphyta) suggests its ancestral nature in the order Hymenoptera - Genetica 146: 341-344

Hirai H, Yamamoto MT, Taylor RW \& Imai HT (1996) Genomic dispersion of 28S rDNA during karyotypic evolution in the ant genus Myrmecia (Formicidae) - Chromosoma 105: 190-196

Hölldobler B \& Wilson EO (2011) The leafcutter ants: civilization by instinct - WW Norton \& Company New York NY 192 pp

Imai HT, Crozier RH \& Taylor RW (1977) Karyotype evolution in Australian ants (Hym Formicidae) - Chromosoma 59: 341-393

Imai HT, Taylor RW, Crosland MWJ \& Crozier RH (1988) Modes of spontaneous chromosomal mutation and karyotype evolution in ants with reference to the minimum interaction hypothesis - The Japanese Journal of Genetics 63: 159-185

Janicki J, Narula N, Ziegler M, Guénard B \& Economo EP (2016) Visualizing and interacting with large-volume biodiversity data using client-server web-mapping applications: the design and implementation of antmapsorg - Ecological Informatics 32: 185-193

Kempf WW (1972) Catálogo abreviado das formigas da região Neotropical - Studia Entomologica 15: 3-344

Kubat Z, Hobza R, Vyskot B \& Kejnovsky E (2008) Microsatellite accumulation on the Y chromosome in Silene latifolia - Genome 51: 350-356

Levan A, Fredga K \& Sandberg AA (1964) Nomeclature for centromeric position on chromosomes - Hereditas 52: 201-220 
Lorite P, Carrillo JA \& Palomeque T (2002) Conservation of (TTAGG)(n) telomeric sequences among ants (Hymenoptera Formicidae) - Journal of Heredity 93: 282-285

Lorite P \& Palomeque T (2010) Karyotype evolution in ants (Hymenoptera: Formicidae) with a review of the known ant chromosome numbers - Myrmecological News 13: 89-102

Lukhtanov VA \& Shapoval NA (2017) Chromosomal identification of cryptic species sharing their DNA barcodes: Polyommatus (Agrodiaetus) antidolus and $P(A)$ morgani in Iran (Lepidoptera Lycaenidae) - Comparative Cytogenetics 11: 759-768

Mayhé-Nunes AJ (1991) Estudo de Acromyrmex (Hymenoptera Formicidae) com ocorrência constatada no Brasil: subsídios para uma análise filogenética - $\mathrm{PhD}$ thesis Universidade Federal de Viçosa Viçosa Brazil 122 pp

Menezes RST, Bardella VB, Cabral-De-Mello DC, Lucena DAA \& Almeida EAB (2017) Are the TTAGG and TTAGGG telomeric repeats phylogenetically conserved in aculeate Hymenoptera? - The Science of Nature 104: 85

Micolino R, Cristiano MP, Travenzoli NM, Lopes DM \& Cardoso DC (2019a) Chromosomal dynamics in space and time: evolutionary history of Mycetophylax ants across past climatic changes in the Brazilian Atlantic coast - Scientific Reports 9: 18800

Micolino R, Cristiano MP \& Cardoso DC (2019b) Population-based cytogenetic banding analysis and phylogenetic relationships of the neotropical fungus-farming ant Trachymyrmex holmgreni Wheeler 1925 - Cytogenetic and Genome Research 159: 151161

Micolino R, Cristiano MP, Cardoso DC (2020) Karyotype and putative chromosomal inversion suggested by integration of cytogenetic and molecular data of the fungus-farming ant Mycetomoellerius iheringiEmery 1888 Comparative Cytogenetics 14(2): 197210 https://doiorg/103897/CompCytogenv14i249846

Palacios-Gimenez OM, Carvalho CR, Soares FAF \& Cabral-De-Mello DC (2015) Contrasting the chromosomal organization of repetitive DNAs in two Gryllidae crickets with highly divergent karyotypes - PLoS ONE 10: e0143540

Pereira TTP, Reis ACCC, Cardoso DC \& Cristiano MP (2018) Molecular phylogenetic reconstruction and localization of the (TTAGG)n telomeric repeats in the chromosomes of Acromyrmex striatus (Roger 1863) suggests a lower ancestral karyotype for leafcutter ants (Hymenoptera) - Comparative Cytogenetics 12: 13-26

Peruzzi L, Eroğlu HE. Karyotype asymmetry: again, how to measure and what to measure? Comp Cytogenet. 2013 Mar 14;7(1):1-9. doi: 10.3897/CompCytogen.v7i1.4431.

Raskina O, Barber JC, Nevo E \& Belyayev A (2008) Repetitive DNA and chromosomal rearrangements: speciation-related events in plant genomes Cytogenetic and Genome Research 120: 351-357 
Raskina O, Belyayev A \& Nevo E (2004) Quantum speciation in Aegilops: molecular cytogenetic evidence from rDNA clusters variability in natural populations - Proceedings of the National Academy of Sciences of the United States of America 101: 14818-14823

Rieseberg LH (2001) Chromosomal rearrangements and speciation - Trends in Ecology and Evolution 16: 351-358

Ruiz-Herrera A, Nergadze SG, Santagostino M \& Giulotto E (2009) Telomeric repeats far from the ends: mechanisms of origin and role in evolution - Cytogenetic and Genome Research 122: $219-228$

Sumner AT (2003) Chromosomes: organization and function - Blackwell Publishing Company Malden MA $287 \mathrm{pp}$

Talavera G, Lukhtanov VA, Rieppel L, Pierce NE \& Vila R (2013) In the shadow of phylogenetic uncertainty: the recent diversification of Lysandra butterflies through chromosomal change - Molecular Phylogenetics and Evolution 69: 469-478

Teixeira GA, Barros LAC, Aguiar HJAC \& Pompolo SG (2017) Comparative physical mapping of 18S rDNA in the karyotypes of six leafcutter ant species of the genera Atta and Acromyrmex (Formicidae: Myrmicinae) - Genetica 145: 351-357

Travenzoli NM, Lima BA, Cardoso DC, Dergam JA, Fernandes-Salomão TM \& Lopes DM (2019) Cytogenetic analysis and chromosomal mapping of repetitive DNA in Melipona species (Hymenoptera Meliponini) - Cytogenetic and Genome Research 158: 213-224

Zanetti R Zanuncio JC Santos JC Da Silva WLP, Ribeiro GT \& Lemes PG (2014) An overview of integrated management of leaf-cutting ants (Hymenoptera: Formicidae) in Brazilian forest plantations - Forests 5: 439-454

Kuznetsova, V, Grozeva, S, Gokhman, V. Telomere structure in insects: A review. J Zool Syst Evol Res. 2020; 58: 127-158. https://doi.org/10.1111/jzs.12332

\section{Table and figure captions}

Table 1: Karyomorphometric analyses of the chromosomes from three different populations of Amoimyrmex silvestrii (Pop. A - Córdoba; Pop. B - Ischilín; and Pop. C - Punilla); and the Amoimyrmex bruchi species. The chromosome total length (TL) and karyotype length (KL) for each sample have been studied here.

Fig. 1: Conventional staining of mitotic metaphases and their respective karyotypes assembled by morphological similarity of three populations of Amoimyrmex silvestrii from the Argentine Chaco (A - Córdoba, B - Ischilín and C-Punilla), as well as Amoimyrmex bruchi. m: metacentric chromosomes. sm: submetacentric chromosomes. Scale bar: $5 \mu \mathrm{m}$. 
476 Fig. 2: DAPI-stained mitotic metaphases from three populations of Amoimyrmex silvestrii, as 477 well as Amoimyrmex bruchi. Left column: fluorescence in situ hybridization (FISH) mapping of 478 the ribosomal DNA (rDNA) 18S cluster (in red). Center column: FISH mapping of the TTAGG $_{(6)}$ 479 telomeric motif (in red). Right column: FISH mapping of the microsatellite $\mathrm{GA}_{(15)}$ (in red). Scale 480 bar: $5 \mu \mathrm{m}$.

481

482 
Am. silvestrii (Pop. A)

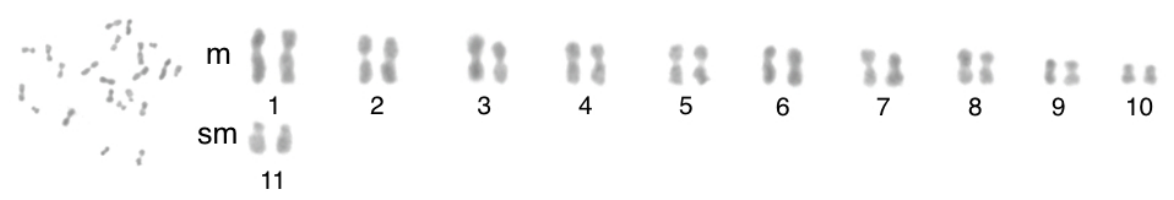

Am. silvestrii (Pop. B)

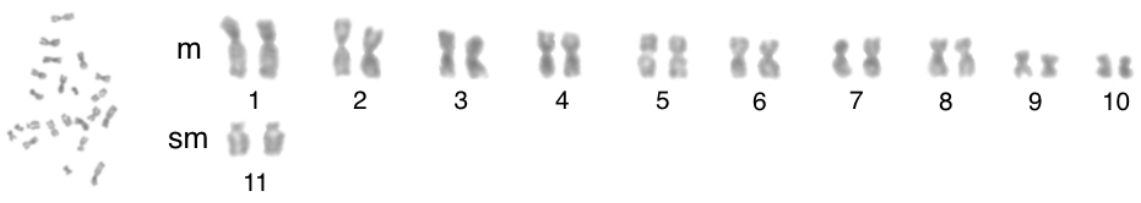

Am. silvestrii (Pop. C)

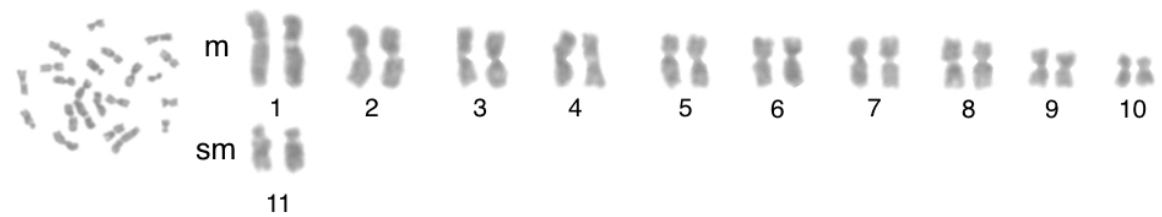

Am. bruchi

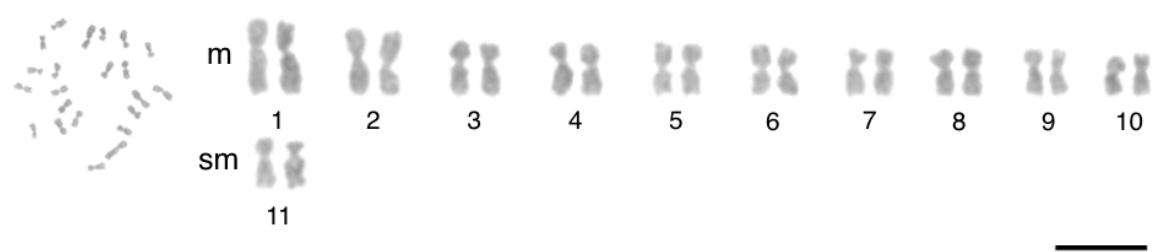

Conventional staining of mitotic metaphases and their respective karyotypes assembled by morphological similarity of three populations of Amoimyrmex silvestrii from the Argentine Chaco ( A - Córdoba, B - Ischilín and C - Punilla), as well as Amoimyrmex bruchi. m: metacentric chromosomes. sm: submetacentric chromosomes. Scale bar: $5 \mu \mathrm{m}$. 


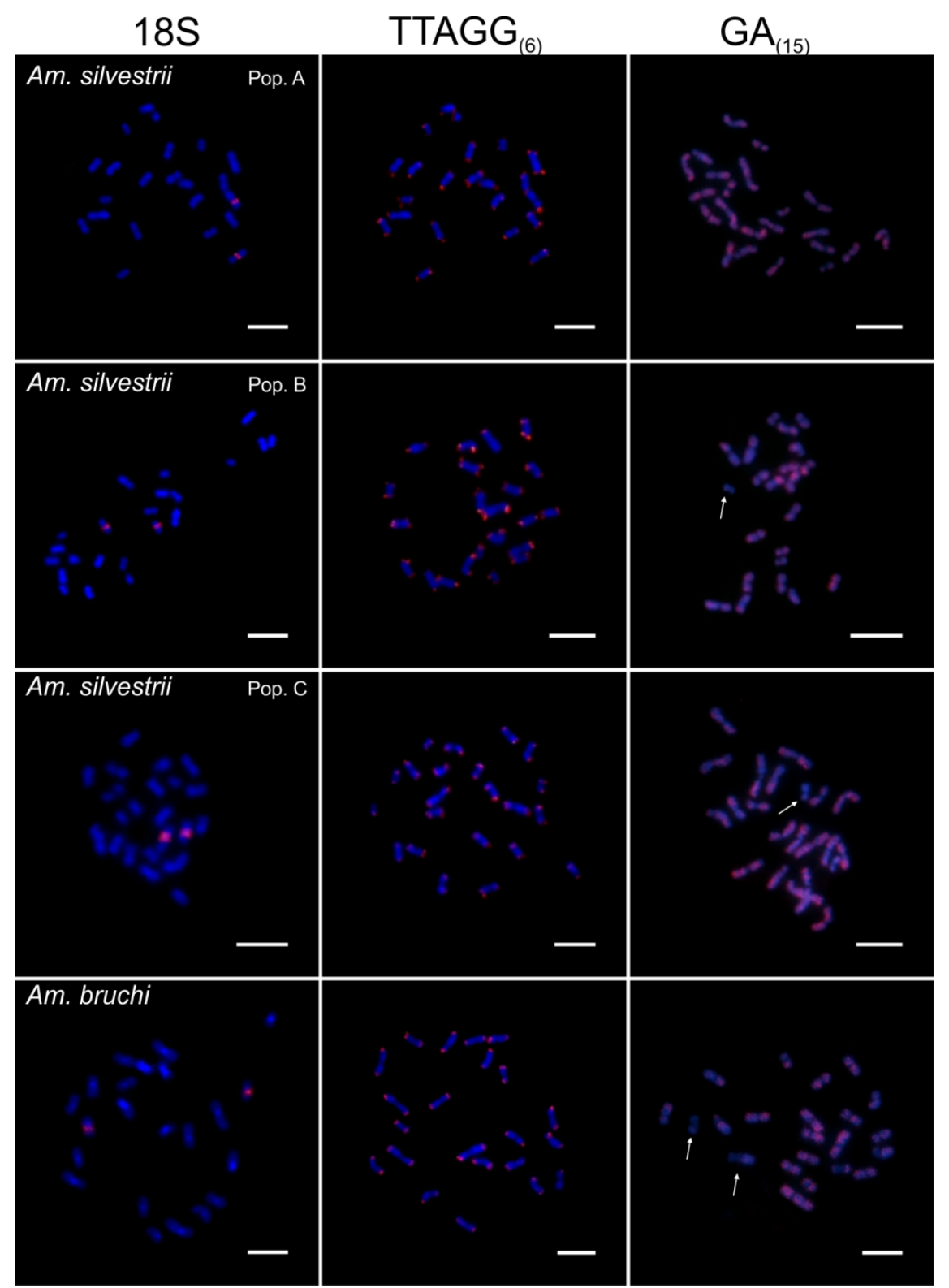

DAPI-stained mitotic metaphases from three populations of Amoimyrmex silvestrii, as well as Amoimyrmex bruchi. Left column: fluorescence in situ hybridization (FISH) mapping of the ribosomal DNA (rDNA) $18 \mathrm{~S}$ cluster (in red). Center column: FISH mapping of the TTAGG(6) telomeric motif (in red). Right column: FISH mapping of the microsatellite GA(15) (in red). Scale bar: $5 \mu \mathrm{m}$. 
Tab. 1:

\begin{tabular}{|c|c|c|c|c|c|}
\hline $\begin{array}{l}\text { Chromosome } \\
\text { (homologous) }\end{array}$ & $\begin{array}{c}\text { Am. silvestrii } \\
\text { Pop. A } \\
\text { TL }(\mu \mathrm{m})\end{array}$ & $\begin{array}{c}\text { Am. silvestrii } \\
\text { Pop. B } \\
\text { TL( } \mu \mathrm{m})\end{array}$ & $\begin{array}{c}\text { Am. silvestrii } \\
\text { Pop. C } \\
\text { TL( } \mu \mathrm{m})\end{array}$ & $\begin{array}{c}\text { Am. bruchi } \\
\mathrm{TL}(\mu \mathrm{m})\end{array}$ & Classification \\
\hline 1 & $3.88 \pm 0.48$ & $3.99 \pm 0.58$ & $4.05 \pm 0.63$ & $3.98 \pm 0.52$ & Metacentric \\
\hline$(1)$ & $3.76 \pm 0.51$ & $3.90 \pm 0.59$ & $3.85 \pm 0.61$ & $3.89 \pm 0.51$ & Metacentric \\
\hline 2 & $3.43 \pm 0.47$ & $3.57 \pm 0.44$ & $3.44 \pm 0.51$ & $3.56 \pm 0.47$ & Metacentric \\
\hline$(2)$ & $3.30 \pm 0.43$ & $3.43 \pm 0.38$ & $3.31 \pm 0.50$ & $3.37 \pm 0.51$ & Metacentric \\
\hline 3 & $3.12 \pm 0.39$ & $3.17 \pm 0.44$ & $3.12 \pm 0.42$ & $2.96 \pm 0.42$ & Metacentric \\
\hline (3) & $3.02 \pm 0.36$ & $3.04 \pm 0.41$ & $3.01 \pm 0.42$ & $2.86 \pm 0.44$ & Metacentric \\
\hline 4 & $2.97 \pm 0.38$ & $2.94 \pm 0.38$ & $2.97 \pm 0.40$ & $2.77 \pm 0.39$ & Metacentric \\
\hline$(4)$ & $2.90 \pm 0.40$ & $2.90 \pm 0.38$ & $2.89 \pm 0.41$ & $2.70 \pm 0.37$ & Metacentric \\
\hline 5 & $2.86 \pm 0.40$ & $2.87 \pm 0.36$ & $2.81 \pm 0.41$ & $2.66 \pm 0.37$ & Metacentric \\
\hline (5) & $2.79 \pm 0.40$ & $2.82 \pm 0.35$ & $2.76 \pm 0.36$ & $2.61 \pm 0.38$ & Metacentric \\
\hline 6 & $2.74 \pm 0.38$ & $2.76 \pm 0.33$ & $2.70 \pm 0.34$ & $2.58 \pm 0.37$ & Metacentric \\
\hline (6) & $2.72 \pm 0.38$ & $2.72 \pm 0.35$ & $2.65 \pm 0.35$ & $2.53 \pm 0.35$ & Metacentric \\
\hline 7 & $2.67 \pm 0.39$ & $2.65 \pm 0.36$ & $2.59 \pm 0.35$ & $2.49 \pm 0.34$ & Metacentric \\
\hline (7) & $2.61 \pm 0.38$ & $2.60 \pm 0.38$ & $2.55 \pm 0.36$ & $2.44 \pm 0.34$ & Metacentric \\
\hline 8 & $2.48 \pm 0.33$ & $2.47 \pm 0.29$ & $2.46 \pm 0.34$ & $2.40 \pm 0.32$ & Metacentric \\
\hline (8) & $2.37 \pm 0.26$ & $2.32 \pm 0.26$ & $2.31 \pm 0.37$ & $2.36 \pm 0.31$ & Metacentric \\
\hline 9 & $1.94 \pm 0.24$ & $2.01 \pm 0.32$ & $2.01 \pm 0.25$ & $2.31 \pm 0.33$ & Metacentric \\
\hline (9) & $1.82 \pm 0.19$ & $1.83 \pm 0.34$ & $1.86 \pm 0.26$ & $2.27 \pm 0.33$ & Metacentric \\
\hline 10 & $1.63 \pm 0.22$ & $1.64 \pm 0.24$ & $1.69 \pm 0.26$ & $2.20 \pm 0.33$ & Metacentric \\
\hline (10) & $1.57 \pm 0.21$ & $1.54 \pm 0.25$ & $1.52 \pm 0.20$ & $1.96 \pm 0.34$ & Metacentric \\
\hline 11 & $2.44 \pm 0.33$ & $2.53 \pm 0.38$ & $2.46 \pm 0.37$ & $2.78 \pm 0.30$ & Submetacentric \\
\hline$(11)$ & $2.33 \pm 0.33$ & $2.38 \pm 0.35$ & $2.34 \pm 0.42$ & $2.61 \pm 0.29$ & Submetacentric \\
\hline$\Sigma(K L)$ & 59.35 & 60.08 & 59.35 & 60.29 & \\
\hline
\end{tabular}

